\title{
Sleep Neurology's Toolkit at the Crossroads: Challenges and Opportunities in Neurotherapeutics Lost and Found in Translation
}

\author{
Erik K. St Louis ${ }^{1,2}$ (1) Aleksandar Videnovic ${ }^{3}$
}

Accepted: 19 February 2021 / Published online: 5 April 2021

(c) The American Society for Experimental NeuroTherapeutics, Inc. 2021

\begin{abstract}
We find ourselves at our present crossroads with a well-traveled toolkit, perhaps too well worn but with aspirational hopes and dreams for the field of sleep neurotherapeutics. This volume is organized thematically into six topical domains that parallel the major subspecialty areas of contemporary clinical sleep neurology practice, as well as novel directions and opportunities. The issue begins with an overview of the central disorders of hypersomnolence, including narcolepsy, idiopathic hypersomnia and other hypersomnia disorders, and the related use of the entire broad range of stimulant and wakepromoting pharmacotherapies. Next, the range of behavioral therapies, application of light and light restriction and melatonin therapies, and hypnotic pharmacotherapies useful in insomnia and circadian sleep-wake rhythm disorders are reviewed, followed by an overview of treatment options for sleep-related breathing disorders including positive airway pressure and the novel approach of hypoglossal neurostimulation for obstructive sleep apnea. The parasomnias and sleep-related movement disorders, including NREM disorders of arousal, REM parasomnias (nightmares and isolated sleep paralysis and idiopathic/isolated REM sleep behavior disorder, and restless legs syndrome are then discussed, and the applications of sleep neurotherapeutics in sleep and neurological disease are reviewed, including neurodevelopmental, epileptic, autoimmune encephalopathies, and neurodegenerative diseases. Last, the novel directions and opportunities in sleep neurology offered by cannabinoid therapies and machine learning/artificial intelligence methodology conclude this comprehensive survey of contemporary sleep neurology. We hope that you find this volume to be a useful and inspirational support tool for the work that matters most, your care of all our sleep neurology patients in the clinics.
\end{abstract}

Key Words Sleep $\cdot$ Neurobiology $\cdot$ Narcolepsy $\cdot$ Sleep disordered breathing $\cdot$ Parasomnia $\cdot$ Restless legs syndrome $\cdot$ Circadian disorders $\cdot$ Therapy

plus ça change, plus c'est la même chose

(the more things change, the more they stay the same)

Jean-Baptiste Alphonse Karr, 1849, and Jon Bon

Jovi/Richie Sambora, 2010

All that is gold does not glitter,

Erik K. St Louis

StLouis.Erik@mayo.edu

1 Mayo Center for Sleep Medicine, Division of Pulmonary and Critical Care Medicine, Departments of Neurology and Medicine, Mayo Clinic College of Medicine and Science, Rochester, MN, USA

2 Department of Clinical and Translational Research, Mayo Clinic Health System Southwest Wisconsin, La Crosse, WI, USA

3 Divisions of Sleep Medicine and Movement Disorders, Department of Neurology, Massachusetts General Hospital, Harvard University, Boston, MA, USA
Not all those who wander are lost;

The old that is strong does not wither,

Deep roots are not reached by the frost...

A light from the shadows shall spring.

J.R.R. Tolkien, The Fellowship of the Ring, 1954

Now my eyes on the far horizon can see a glow

Announcin' things ain't what they used to be.

Mercer Ellington and Ted Persons, 1942

\section{Introduction}

After the most challenging and bizarre year 2020 has drawn to a close and as the COVID-19 pandemic hopefully now appears to be reaching its denouement as the vaccination efforts roll out in earnest, we in the fields of sleep neurology and neurotherapeutics find ourselves at a crossroads. At this juncture and time, we reflect on the relative value, merits, 
and pitfalls between the old and the new, the clinics and telehealth [1-3], the lab, and the home [4, 5]. In our field especially, we reflect on and weigh the old faithful standby diagnostics and remedies against the hope for novel, widely accessible sleep diagnostics and neurotherapeutics.

While some of these exciting trends in sleep neurology had begun well before the pandemic, the unprecedented challenge of COVID-19 to healthcare providers and patients worldwide has also forced immediate and broad sweeping innovation and change in professional norms and practices and shifting patient values and preferences [6]. We have been inspired and energized by the resilience and malleability of our colleagues and patients alike through these most turbulent times, while we also mourn the losses and strife that COVID-19 has unveiled and magnified; the full extent of the many ills in our societies, especially exposing the terrible truths of health, economic, and racial disparities, and the tragic consequences of large scale loss of lives, pain, and suffering. The challenges of COVID-19 to sleep neurology specifically have included an apparent co-pandemic of "COVID-somnia" sleeplessness in our communities [7-10], closure of sleep laboratory testing facilities, and dramatic shifts toward home monitoring and clinical care delivery models. Yet, we are hopeful that as broad-scale vaccination becomes available, a new dawn of possibility, inspiration, innovation, and justice will emerge in both our world and our field.

This is a time to reflect on what the past has brought us, and where we might head. We reflect gratefully on the firm scientific foundation of the past century laid by the work of the founding giants of our sleep and neuropsychiatric disciplines, including Von Economo [11, 12], Berger [13-15], Aserinsky and Kleitman [16-18], and Rechtschaffen and Kales [19], among so many others. We also celebrate the achievements and lives and mourn the loss of our modern era sleep heroes Dement [20], Jouvet [21], Guilleminault [22], and Mahowald [23]. We are inspired by the substantial additional advances during the last two decades in particular, which have exponentially improved our understanding of basic and clinical sleep sciences and the crucial impact of sleep on brain and general health, revealing network mechanisms and functioning of the non-rapid eye movement (NREM) and rapid eye movement (REM) sleep switches [24, 25], the brain's glymphatic system [26], and its possible roles in brain health, aging, and neurodegeneration, and the synaptic homeostasis hypothesis [27]. In parallel, in sleep neurology and science, key advances with more direct clinical applicability have included understanding genetic vulnerability and hypocretinergic deficiency in narcolepsy [28-31], elucidation of arousal systems underlying NREM parasomnia [32], clarification of the pontomedullary network that mediates REM atonia control system mechanisms [33], and formative evidence of the relationship between brain iron deficiency and network dysfunction underlying restless legs syndrome [34], which are just a few examples of the impressive advances in sleep neurology reviewed by our expert authors in this volume. Recognition of REM sleep behavior disorder as the most important prodromal manifestation of disorders associated with synuclein-specific neurodegeneration, such as Parkinson disease and dementia with Lewy bodies, has provided an extraordinary opportunity to employ promising agents and slow the progression of these chronic neurodegenerative disorders [35-38]. The circadian system and its underlying biological principles, serving a crucial role in physiological and behavioral homeostasis, received broader, long-overdue recognition with the awarding of the 2017 Nobel Prize in Medicine or Physiology to Drs. Jeffrey Hall, Michael Rosbash, and Michael Young [39]. Beyond the scope of the circadian rhythm sleep disorders, this will lead to a renewed appreciation and recognition of the immense potential for circadian-based principles and interventions in reducing disease burden across a wide range of neuropsychiatric and medical disorders [40].

Yet only recently have these seminal advances in sleep clinical and translational neuroscience begun directly to enable new therapeutic possibilities and rational and specific therapies. A few examples of such pivotal developments reviewed in this issue include hypocretin antagonism for insomnia [41], pitolisant for narcolepsy [42], and hypoglossal nerve stimulation for obstructive sleep apnea [43, 44]. But much more work remains to improve understanding of basic sleep and circadian neurobiology and ultimately enable the translation of these advances via rationally based, randomized controlled trials targeting specific pathophysiologic mechanisms into a broader therapeutic armamentarium for our patients who suffer from insomnia, hypersomnia, sleepdisordered breathing, parasomnias, and sleep-related movement disorders.

We find ourselves at our present crossroads with only a well-traveled toolkit, perhaps too well worn in some respects, but with aspirational hopes and dreams for the field of sleep neurotherapeutics. Despite the advances of knowledge and understanding in sleep neuroscience and the recognition of the pivotal role of sleep in brain health, there has been very little movement or change in several therapeutic areas in well over a decade (and in some cases, much longer), which naturally leads to disappointment. But like a trusty old watch, a well-worn doctor's bag, or a threadbare great coat providing seasonal winter warmth, our available tools also bring comfort in their familiarity and inspire gratitude for their remaining utility and applicability. We really still need them all, but we yearn for even more!

The standby therapeutics from our old toolkit that are still most useful in sleep neurology include the broad range of stimulants and wake-promoting agents and hypnotics and the unfortunately narrow medication options available for 
restless legs syndrome and the parasomnias. These tools remain reliable and useful but have begun to feel a bit tired, worn, and dusty, so we are hopeful for innovation coming to these areas in the near future. But for the time being, we will make do with the old and hope that the expert contemporary applications and approaches of these therapies outlined herein will serve you well.

Encouragingly, some new twists, improvements, and enhancements have indeed become recently available in sleep neurotherapeutics. Pharmacotherapies with novel wrinkles in their putative mechanisms of action are now available for the treatment of hypersomnias and insomnia including pitolisant, a novel histaminergic wake-promoting agent [42]; and suvorexant and lemborexant [41], which exert their sleep-inducing actions by hypocretin antagonism. The management of sleep-related breathing disorders has also been greatly enhanced by the availability of "smarter," auto-titrating positive airway pressure devices offering patients and practitioners greatly improved analytics and remote-monitoring capabilities better to measure treatment outcomes, expand access for monitoring broader populations of patients, and enhance patient tolerability [45]. Recent clinical trials have also demonstrated the utility of bright light therapy in selected circadian disorders, especially for application in neurodegenerative populations such as those with Parkinson disease [46]. Neuromodulation has seen its first sleep-medicine application of hypoglossal nerve stimulation in the treatment of obstructive sleep apnea [43]. So, we have indeed seen real and gratifying progress in several areas. However, neuromodulatory approaches remain a frontier for exploration in areas such as slow-wave and sleep-spindle enhancement. Determining whether such sleep-enhancement approaches are efficacious in improving sleep quality and cognition in healthy child and adult populations and diseased patients is a significant and unfulfilled opportunity at present $[47,48]$. Neuropharmacologic approaches should also continue to progress in parallel with future advances in sleep neurobiology and the understanding of disease mechanisms.

This volume is organized thematically into six topical domains that parallel the five major subspecialty areas of contemporary clinical sleep neurology practice, as well as the sixth topic of novel directions and opportunities. The issue begins with an overview of the central disorders of hypersomnolence, including narcolepsy [49], idiopathic hypersomnia and other hypersomnia disorders [50], and the related use of the entire broad range of stimulant and wakepromoting pharmacotherapies. Next, the range of behavioral therapies [51], application of light and light restriction and melatonin therapies [52], and hypnotic pharmacotherapies useful in insomnia [53] and Circadian sleep-wake rhythm disorders are reviewed, followed by an overview of treatment options for sleep-related breathing disorders including continuous positive airway pressure (CPAP [54]), advanced positive airway pressure (PAP) modalities [55], and the novel approach of hypoglossal neurostimulation for obstructive sleep apnea patients who are intolerant to PAP or other therapies [56]. The parasomnias and sleep-related movement disorders, including NREM disorders of arousal [57], REM parasomnias (nightmares and isolated sleep paralysis [58] and idiopathic/isolated REM sleep behavior disorder [35]), and restless legs syndrome [59], are then discussed, and the applications of sleep neurotherapeutics in sleep and neurological disease are then reviewed, including neurodevelopmental [60], epileptic [61], autoimmune encephalopathies [62], and neurodegenerative diseases and disorders [63]. Last, the novel directions and opportunities in sleep neurology offered by cannabinoid therapies [64] and machine learning/artificial intelligence methodology [65] conclude this comprehensive survey of contemporary sleep neurology.

This issue of Neurotherapeutics is truly the enactment of a dream initially forged well over a year ago in Vancouver at the World Sleep Congress. Our goal then was to assemble a "dream team" of world-wide experts to provide a comprehensive, state-of-the-art survey of the clinical fields of sleep neurology and neurotherapeutics. Would they agree? Happily, yes, and gradually, the topics took shape, and each of our colleagues generously gave their time and brought their energy and expertise, until this now complete volume has emerged. We are so grateful for their manifold contributions and hard work. We also wish to thank Drs. Greg Bergey, Associate Editor; and M. Maral Mouradian, Editor-in-Chief; Ms. Linda Powell, Editorial Manager; and the entire editorial staff of Neurotherapeutics for their guidance, patience, mediation, curation, and expert collation and copy editing of these works along the way. We hope you will appreciate, enjoy, and profit from the fruits of all of our colleagues' labors. Most of all, we hope that you find this volume to be a useful and inspirational support tool for the work that matters most, your care of all our sleep neurology patients in the clinics.

Erik K. St Louis, M.D., M.S.

Alekssandar Videnovic, M.S., M.Sc.

Guest Editors, Neurotherapeutics Sleep Neurology Edition

Supplementary Information The online version contains supplementary material available at https://doi.org/10.1007/s13311-021-01032-7.

Acknowledgements We are also grateful to Ms. Lea Dacy, Mayo Clinic Department of Neurology, for secretarial assistance with manuscript formatting and submission.

Required Author Forms Disclosure forms provided by the authors are available with the online version of this article. 
Funding This publication was supported by NIH/NCRR/NCATS CCaTS Grant Numbers UL1 TR002377, NIH/NIA R34AG056639 (NAPS), NIH/NINDS R01NS099055, and NIH/NINDS R21NS108022.

\section{Declarations}

Disclaimer The contents of this publication are solely the responsibility of the authors and do not necessarily represent the official views of the NIH.

\section{References}

1. Schutte-Rodin S. Telehealth, telemedicine, and obstructive sleep apnea. Sleep Med Clin 2020;15:359-375.

2. Singh J, Badr MS, Diebert W, et al. American academy of sleep medicine (aasm) position paper for the use of telemedicine for the diagnosis and treatment of sleep disorders. J Clin Sleep Med 2015;11:1187-1198

3. Singh J, Keer N. Overview of telemedicine and sleep disorders. Sleep Med Clin 2020;15:341-346.

4. Collop NA, Anderson WM, Boehlecke B, et al. Clinical guidelines for the use of unattended portable monitors in the diagnosis of obstructive sleep apnea in adult patients. Portable monitoring task force of the american academy of sleep medicine. J Clin Sleep Med 2007;3:737-747.

5. Khosla S, Deak MC, Gault D, et al. Consumer sleep technology: An american academy of sleep medicine position statement. J Clin Sleep Med 2018;14:877-880.

6. Voulgaris A, Ferini-Strambi L, Steiropoulos P. Sleep medicine and covid-19. Has a new era begun? Sleep Med 2020;73:170-176.

7. Hurley D. Sleep neurologists call it 'covid-somnia'-increased sleep disturbances linked to the pandemic. Neurology Today 2020;20:1-31.

8. Pappa S, Ntella V, Giannakas T, Giannakoulis VG, Papoutsi E, Katsaounou P. Prevalence of depression, anxiety, and insomnia among healthcare workers during the covid-19 pandemic: A systematic review and meta-analysis. Brain Behav Immun 2020;88:901-907.

9. Perez-Carbonell L, Meurling IJ, Wassermann D, et al. Impact of the novel coronavirus (covid-19) pandemic on sleep. J Thorac Dis 2020;12:S163-S175

10. Shi L, Lu ZA, Que JY, et al. Prevalence of and risk factors associated with mental health symptoms among the general population in china during the coronavirus disease 2019 pandemic. JAMA Netw Open 2020;3:e2014053.

11. Saper CB, Chou TC, Scammell TE. The sleep switch: Hypothalamic control of sleep and wakefulness. Trends Neurosci 2001;24:726-731

12. Von Economo J. Sleep as a problem of localization. J Nerv Ment Dis 1930;71:249-259.

13. Gloor P. The work of hans berger. Electroencephalogr Clin Neurophysiol 1969;27:649.

14. Karbowski K. Hans berger (1873-1941). J Neurol 2002;249:1130-1131.

15. La Vaque TJ. The history of eeg hans berger psychophysiologist. A historical vignette. J Neurother 2008;3:1-9.

16. Aserinsky E, Kleitman N. Regularly occurring periods of eye motility, and concomitant phenomena, curing sleep. Science 1953;118:273-274.

17. Dement WC. Remembering nathaniel kleitman. Arch Ital Biol 2001;139:11-17.
18. Kleitman N. Sleep and wakefulness. 2nd ed. Chicago: University of Chicago Press 1963.

19. Rechtschaffen A, Kales A, editors. A manual of standardized terminology, techniques and scoring system for sleep stages of human subjects. Washington DC: U.S. Public Health Service, U.S. Government Printing Office 1968.

20. Sandomir R. Dr. William dement, leader in sleep disorder research, dies at 91. New York Times 2020 June 30;Sect. B.

21. Dement WC, Pelayo R. Reminiscences of michel jouvet. Sleep Med 2018;49:78-80.

22. Szymusiak R, Manber R. Remembering the contributions of christian guilleminault to sleep. Sleep 2019;42.

23. Langendorf FG, Anderson DC. In memoriam mark w. Mahowald, md (1943-2020). Neurology 2020;94:1062-1063.

24. Horner RL, Peever JH. Brain circuitry controlling sleep and wakefulness. Continuum (Minneap Minn) 2017;23:955-972.

25. Saper CB, Fuller PM, Pedersen NP, Lu J, Scammell TE. Sleep state switching. Neuron 2010;68:1023-1042.

26. Nedergaard M, Goldman SA. Glymphatic failure as a final common pathway to dementia. Science 2020;370:50-56.

27. Tononi G, Cirelli C. Sleep and the price of plasticity: From synaptic and cellular homeostasis to memory consolidation and integration. Neuron 2014;81:12-34.

28. Chemelli RM, Willie JT, Sinton CM, et al. Narcolepsy in orexin knockout mice: Molecular genetics of sleep regulation. Cell 1999;98:437-451.

29. Hara J, Beuckmann CT, Nambu T, et al. Genetic ablation of orexin neurons in mice results in narcolepsy, hypophagia, and obesity. Neuron 2001;30:345-354.

30. Mignot E, Hayduk R, Black J, Grumet FC, Guilleminault C. Hla dqb1*0602 is associated with cataplexy in 509 narcoleptic patients. Sleep 1997;20:1012-1020.

31. Tabuchi S, Tsunematsu T, Black SW, et al. Conditional ablation of orexin/hypocretin neurons: A new mouse model for the study of narcolepsy and orexin system function. J Neurosci 2014;34:6495-6509.

32. Castelnovo A, Lopez R, Proserpio P, Nobili L, Dauvilliers Y. Nrem sleep parasomnias as disorders of sleep-state dissociation. Nat Rev Neurol 2018;14:470-481.

33. Peever J, Luppi PH, Montplaisir J. Breakdown in rem sleep circuitry underlies rem sleep behavior disorder. Trends Neurosci 2014;37:279-288.

34. Connor JR, Patton SM, Oexle K, Allen RP. Iron and restless legs syndrome: Treatment, genetics and pathophysiology. Sleep Med 2017;31:61-70.

35. Matar E, McCarter SJ, St Louis EK, Lewis SJG. Current concepts and controversies in the management of rem sleep behavior disorder. Neurotherapeutics 2021.

36. Postuma RB, Iranzo A, Hu M, et al. Risk and predictors of dementia and parkinsonism in idiopathic rem sleep behaviour disorder: A multicentre study. Brain 2019;142:744-759.

37. Schenck CH, Montplaisir JY, Frauscher B, et al. Rapid eye movement sleep behavior disorder: Devising controlled active treatment studies for symptomatic and neuroprotective therapy--a consensus statement from the international rapid eye movement sleep behavior disorder study group. Sleep Med 2013;14:795-806.

38. Videnovic A, Ju YS, Arnulf I, et al. Clinical trials in rem sleep behavioural disorder: Challenges and opportunities. J Neurol Neurosurg Psychiatry 2020;91:740-749.

39. Sehgal A. Physiology flies with time. Cell 2017;171:1232-1235.

40. Videnovic A, Lazar AS, Barker RA, Overeem S. 'The clocks that time us'--circadian rhythms in neurodegenerative disorders. Nat Rev Neurol 2014;10:683-693. 
41. Winrow CJ, Renger JJ. Discovery and development of orexin receptor antagonists as therapeutics for insomnia. $\mathrm{Br} \mathrm{J}$ Pharmacol 2014;171:283-293.

42. Lamb YN. Pitolisant: A review in narcolepsy with or without cataplexy. CNS Drugs 2020;34:207-218.

43. Certal VF, Zaghi S, Riaz M, et al. Hypoglossal nerve stimulation in the treatment of obstructive sleep apnea: A systematic review and meta-analysis. Laryngoscope 2015;125:1254-1264.

44. Olson MD, Junna M. Hypoglossal nerve stimulation therapy for the treatment of obstructive sleep apnea. Neurotherapeutics 2021;18.

45. Brown LK, Javaheri S. Positive airway pressure device technology past and present: What's in the "black box"? Sleep Med Clin 2017;12:501-515.

46. Videnovic A, Klerman EB, Wang W, Marconi A, Kuhta T, Zee PC. Timed light therapy for sleep and daytime sleepiness associated with parkinson disease: A randomized clinical trial. JAMA Neurol 2017;74:411-418.

47. Zhang Y, Gruber R. Can slow-wave sleep enhancement improve memory? A review of current approaches and cognitive outcomes. Yale J Biol Med 2019;92:63-80.

48. Malkani RG, Zee PC. Brain stimulation for improving sleep and memory. Sleep Med Clin 2020;15:101-115.

49. Piazzi G. Pharmacological and behavioral treatment: Strategies for narcolepsy. Neurotherapeutics 2021.

50. Trotti LM, Arnulf I. Idiopathic hypersomnia and other hypersomnia syndromes. Neurotherapeutics 2020.

51. Yan Chana N, Yan Chana JW, Xin Li S, Wing YK. Nonpharmacological approaches for management of insomnia. Neurotherapeutics, in press 2021.

52. Steele TA, St Louis EK, Videnovic A, Auger RR. Circadian rhythm sleep-wake disorders: A contemporary review of neurobiology, treatment, and dysregulation in neurodegenerative disease. Neurotherapeutics, in press 2021.
53. Madari S, Golebiowski R, Mansukhani MP, Kolla BP. Pharmacological management of insomnia. Neurotherapeutics 2021.

54. Raphelson JR, Kreitinger KY, Malhotra A. Positive airway pressure therapy in sleep-disordered breathing. Neurotherapeutics 2020.

55. Selim B, Ramar K. Sleep-related breathing disorders: When cpap is not enough. Neurotherapeutics 2020.

56. Junna M, Olson M. Hypoglossal nerve stimulation for obstructive sleep apnea. Neurotherapeutics, in press 2021.

57. Irfan $\mathrm{M}$, Schenck $\mathrm{CH}$, Howell MJ. Nonrem disorders of arousal and related parasomnias: An updated review. Neurotherapeutics 2021.

58. Stefani A, Hogl B. Nightmare disorder and isolated sleep paralysis. Neurotherapeutics 2020.

59. Gossard TR, Trotti LM, Videnovic A, St Louis EK. Restless legs syndrome: Contemporary diagnosis and treatment. Neurotherapeutics 2021.

60. Shelton AR, Malow B. Neurodevelopmental disorders commonly presenting with sleep disturbances. Neurotherapeutics 2021.

61. Moore JL, Carvalho DZ, Bazil CW, St Louis EK. Sleep and epilepsy: A focused review of pathophysiology, clinical syndromes, co-morbidities, and therapy. Neurotherapeutics, in press 2021.

62. Devine M, St Louis EK. Sleep disturbances associated with neurological autoimmunity. Neurotherapeutics 2021.

63. Voysey ZJ, Barker RA, Lazar AS. The treatment of sleep dysfunction in neurodegenerative disorders. Neurotherapeutics 2020.

64. Zee P. Effects of cannabinoids on sleep and their therapeutic potential for sleep disorders. Neurotherapeutics 2021.

65. Redline S. Machine and deep learning in molecular and genetic aspects of sleep research. Neurotherapeutics 2021.

Publisher's Note Springer Nature remains neutral with regard to jurisdictional claims in published maps and institutional affiliations. 